\title{
Prevalence of Morbidities among Peri-Menopausal and Postmenopausal Women in Selected Urban Slums of Eastern India
}

\section{Kamal Kishor Dewangan ${ }^{1}$, Sumitra Pattanaik², Lipilekha Patnaik², Trilochan Sahu ${ }^{3}$}

'Post Graduate Resident, Department of Community Medicine, IMS and SUM Hospital, Bhubaneswar, India; ${ }^{2}$ Professor, Department of Community Medicine, IMS and SUM Hospital, Bhubaneswar, India; 3Professor and Head, Department of Community Medicine, IMS and SUM Hospital, Bhubaneswar, India.

\section{ABSTRACT}

Background: Women having menstrual Menopause is a universal physiological transitional process of the reproductive phase to the nonreproductive phase of life. During this transition, women suffer somatic, psychological and urogenital morbidities those are due to a decrease in the level of oestrogen that affects their quality of life.

Objective: To find out the prevalence of morbidities among perimenopausal women using Modified Menopausal Rating Scale (MRS) and their associated factors of morbidities.

Methods: It is a community-based cross-sectional study conducted on selected 9 urban slums under Urban Health Training Centre area of IMS and SUM Hospital, Bhubaneswar in September to November 2018. probability sampling method was used and the sample size calculated was 220. Perception of morbidities using Modified Menopausal Rating Scale was used. Data were entered in excel spreadsheet and analysis done by using SPSS VS.20.

Results: The mean age of menopausal women in the study was $49.35 \pm 5.4$ years and the majority were in the age group was 51-55years (35.4\%). The most common perceived symptoms were joint and muscular discomfort (92.27\%), anxiety (72.72\%), hot flushes and physical mental exhaustion (71\%), bladder problem (67.2\%), sleep problem (62.27\%), heart discomfort and irritability (57\%), Depression (55.9\%), sexual problem (56.36\%) and vaginal dryness (55\%).

Conclusions: Depression and physical and mental exhaustion complaints were high among perimenopausal women. The severity of morbidities was higher among postmenopausal women in somatic and urogenital subscales, Illiteracy and the high proportion of low SES made the menopausal quality of life worse in slum population.

Key Words: Modified menopausal Rating Scale (MRS), Menopausal morbidity, Urban slums.

\section{BACKGROUND}

Menopause is a specific physiological transition from reproductive to the non-reproductive phase of women's life. ${ }^{1}$ Due to rapid globalization, urbanization, awareness and increase longevity in urban middle-aged Indian women, menopause problems are emerging as an issue in the world leading to morbidities. According to the World Health Organization menopause defined as "Permanent cessation of menstruation resulting from loss of ovarian follicular activity" and postmenopause as the 12 months after natural amenorrhea. ${ }^{2,3}$ It occurs due to a reduction in the number of ovarian follicles about to end, but natural declining of secretion of the ovarian hormone ${ }^{4}$ Perimenopausal period defines the time before; during and after menopause. Complains that start with the menopausal transition typically continue making a compensatory decrease in the Post-menopause. ${ }^{5}$ According to Population Projection Survey in India 45 years and above is expected to increase in 401 million in 2026 and at the present 96 million population. These enormous numbers of women are predicted to approx. 30 years post-reproductive period of life. ${ }^{6}$ Women achieved menopause through various ways as spontaneous decreasing of reproductive hormones, hysterectomy, due to deficiency of primary ovarian and chemo and radiation therapy. ${ }^{7}$

\section{Corresponding Author:}

Dr. Kamal Kishor Dewangan, Post Graduate Resident, Department of Community Medicine, IMS and SUM Hospital, Bhubaneswar, India; E-mail: drkamaldewangan@gmail.com

ISSN: $2231-2196$ (Print)

Received: 26.06 .2020
ISSN: $0975-5241$ (Online)

Revised: 07.08 .2020
Accepted: 03.09.2020 
Worldwide, the mean age of menopause ranges from 40-65 years. During the menopausal transitional phase, women experience vasomotor, psychosomatic, urogenital as well as sexual complaints. So, theses morbidities effect decreasing the quality of life and make susceptible for early mortality from following chronic diseases like Osteoporosis, Ischemic Heart Disease etc. ${ }^{8}$ According to Indian Menopause Society menopause of Indian women average is 47.5 years. It was much less than westerns countries (51years), Hence menopausal health in Indian scenario should be higher priority. ${ }^{9}$

Objective: To find out the prevalence of morbidities among perimenopausal women using Modified Menopausal Rating Scale (MRS) and their associated factors.

\section{MATERIALS AND METHODS}

This study was conducted in selected urban slums of Bhubaneswar catered under Urban Health Training Centre of Department of Community medicine, Bhubaneswar, Odisha. It was a cross-sectional study, of 3 months duration from September 2018 to November 2018.

\section{Inclusion criteria:}

1. Women of 40-60 years age group.

2. Who willing to take part in the study and had given informed consent

\section{Exclusion criteria}

Having any systemic illness and on hormonal replacement therapy or hysterectomy is done in past. The sampling technique used convenient sampling, the slums and menopausal women were identified from the urban field practice area of the medical college and included in the study.For sample size calculation conducting a pilot study on 30 women and prevalence of major menopausal symptoms found was $60 \%$, Sample size formula $\mathrm{N}=4 \mathrm{PQ} / \mathrm{L}^{2}, \mathrm{P}=60 \%, \mathrm{Q}=40 \%, \mathrm{~L}=10 \%$ (Absolute precision) with $95 \%$ Confidence interval, 2 design effect for sampling, $10 \%$ non-response rate, total sample size was calculated 220 .

Study tool: Among participants a conducting interview using Menopausal Rating Scale (MRS), this tool already validated through various authors and broadly used for capturing the menopausal morbidities and their quality of life indexing, before the interview informed consent had been taken from participants.

MRS consists of 11 items and separated into subscale categories

a. Somatic: Hot flushes/sweat discomfort, heart discomfort/palpitation, sleeping discomfort then joint and muscle ached complains)

b. Psychological: Depressive mood complains, irritability, anxiety status, physical and mental exhaustion conditions

c. Urogenital: Sexual complains, bladder discomfort, and vaginal dryness.

The scoring each item can be graded from the point by point rises by its severity of perceived complains. It's 11 complaining items of indexing quality of life scale, each complaining item classified from $0-4,(0=$ no complain/normal $)$, $(1=$ mild $),(2=$ moderate $),(3=$ severe $),(4=$ very severe $)$ MRS assortment between 0 (lowest level of complain) and 44 (maximal gradation of complain) ${ }^{10}$

The gradation of lowest/highest score differ between three subscale categories according to their number of perceived problems distributed to their categorised under subscale

For somatic subscale category classified into those who received score 0 to 2 categorised under no complains/few complains, 3 to 4 have under mild complains then 5 to 8 under moderate complains last score $>8$, under severe complains.

Psychological category those who received score 0 to 1 classified under lowest or few complains, 2 to 3 have under mild complains then 4 to 6 have moderate complains last $>6$, classified severe complaints.

Urogenital category those who got score 0 , classified under lowest / few complaints, 1 to have under mild complains, 2 to 3 have moderate complains then $>3$ classified under severe complain. ${ }^{10}$

Statistical analysis: data were entered in the excel spreadsheet and for SPSS version 20 was used for analysis. Chisquare test was used to analyse quantitative variables. Continuous data were expressed as mean \pm SD, (95\% C.I.), $\mathrm{P}$-value $<0.05$ was taken statistically significant.

\section{RESULTS}

\section{Table 1: Distribution of study population according to sociodemographic factors}

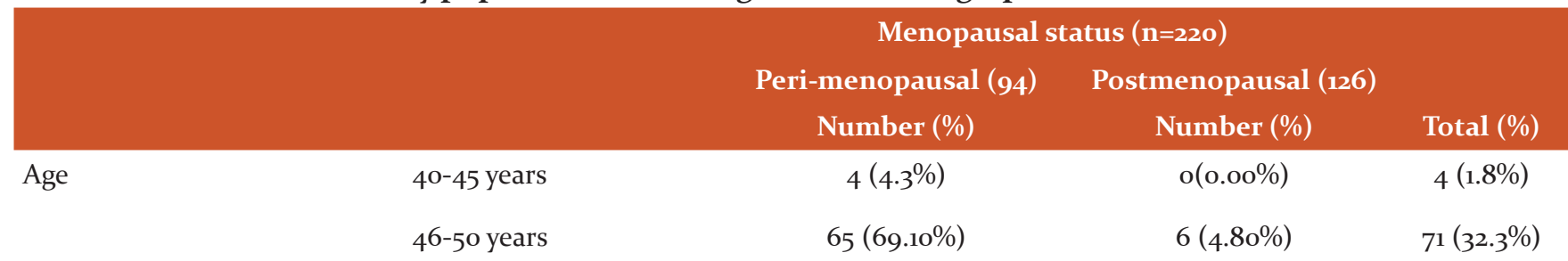


Table 1: (Continued)

\begin{tabular}{|c|c|c|c|c|}
\hline & & Menopausal & tus $(n=220)$ & \\
\hline & & Peri-menopausal (94) & Postmenopausal (126) & \\
\hline & & Number (\%) & Number (\%) & Total (\%) \\
\hline & $51^{-}-55$ years & $25(26.60 \%)$ & $53(42.10 \%)$ & $78(35.4 \%)$ \\
\hline & $56-60$ years & o $(0.00 \%)$ & $67(53.20 \%)$ & $67(30.4 \%)$ \\
\hline Religion & Hindu & $88(93.60 \%)$ & $115(91.30 \%)$ & $203(92.3 \%)$ \\
\hline & Muslim & $6(6.40 \%)$ & $11(8.70 \%)$ & $17(7 \cdot 7 \%)$ \\
\hline Caste & General & $51(54 \cdot 30 \%)$ & $62(49.20 \%)$ & $113(51.4 \%)$ \\
\hline & ОВС & $32(34.00 \%)$ & $58(46.00 \%)$ & $90(40.9 \%)$ \\
\hline & ST & $8(8.50 \%)$ & $6(4.80 \%)$ & $14(6.4 \%)$ \\
\hline & SC & $3(3.20 \%)$ & $\mathrm{o}(0.00 \%)$ & $3(1.4 \%)$ \\
\hline Family & Nuclear & $49(52.10 \%)$ & $48(38.10 \%)$ & $97(44.1 \%)$ \\
\hline & Joint & $45(47.90 \%)$ & $78(61.90 \%)$ & $123(55.9 \%)$ \\
\hline Marital status & Married & $91(96.80 \%)$ & $118(93.70 \%)$ & $209(95 \%)$ \\
\hline & Separated & $1(1.10 \%)$ & $3(2.40 \%)$ & $4(1.8 \%)$ \\
\hline & Widow & $2(2.10 \%)$ & $5(4.00 \%)$ & $7(3.2 \%)$ \\
\hline No.of children & o & $1(1.10 \%)$ & $3(2.40 \%)$ & $4(1.8 \%)$ \\
\hline & 1 & $\mathrm{o}(0.00 \%)$ & $4(3.20 \%)$ & $4(1.8 \%)$ \\
\hline & 2 & $21(22.30 \%)$ & $27(21.40 \%)$ & $48(21.8 \%)$ \\
\hline & $\geq 3$ & $72(76.60 \%)$ & $92(73 \%)$ & $164(74.5)$ \\
\hline Education category & Illiterate & $23(24.50 \%)$ & $83(65.90 \%)$ & $106(48.2 \%)$ \\
\hline & Primary & $26(27 \cdot 70 \%)$ & $30(23.80 \%)$ & $56(25.4 \%)$ \\
\hline & Middle School & $24(25.50 \%)$ & $11(8.70 \%)$ & $35(15.9 \%)$ \\
\hline & High school & $21(22.30 \%)$ & $2(1.60 \%)$ & $23(10.4 \%)$ \\
\hline Occupation & Labor & $69(73.40 \%)$ & $79(62.70 \%)$ & $148(67.3 \%)$ \\
\hline & Housewife & $23(24.50 \%)$ & $45(35 \cdot 70 \%)$ & $68(30.9 \%)$ \\
\hline & Small shops & $2(2.10 \%)$ & $2(1.60 \%)$ & $4(1.8 \%)$ \\
\hline Socio-Economic-Status & Upper middle & $2(2.10 \%)$ & $1(0.80 \%)$ & $3(1.3)$ \\
\hline & Lower middle & $9(9.60 \%)$ & $12(9.50 \%)$ & $21(9.5 \%)$ \\
\hline & Upper lower & $51(54 \cdot 30 \%)$ & $65(51.60 \%)$ & $116(52.7 \%)$ \\
\hline & Lower & $32(34.00 \%)$ & $48(38.10 \%)$ & $80(36.4 \%)$ \\
\hline
\end{tabular}

Table 1 shows the distribution of the study population according to socio-demographic factors. Out of 220 women, $35.4 \%$ of women were in the age group of 51-55years. 126 postmenopausal women revealed their menopausal age. Mean age of menopause in the study was found to be 49.35 \pm 5.4 . The majority were Hindu (92.6\%), followed by Mus$\lim (7.7 \%)$, among them General category $(51.4 \%)$ followed by $\mathrm{OBC}(41 \%)$ and ST/SC (7.8\%). Structure of family ma- jority was in Joint family (55.9\%) type, $95 \%$ of respondents were married and most of the respondents have 3 or more children. Mostly half of the participants (48.2\%) were illiterate by their educational status, Majority of participants $(67.3 \%)$ working labourer by profession and $52.7 \%$ of study participants belonging to Upper lower Socioeconomic status according to modified Kuppuswamy 2018 Socioeconomic rating scale. ${ }^{11}$ 
Table 2: Prevalence of peri and postmenopausal symptoms

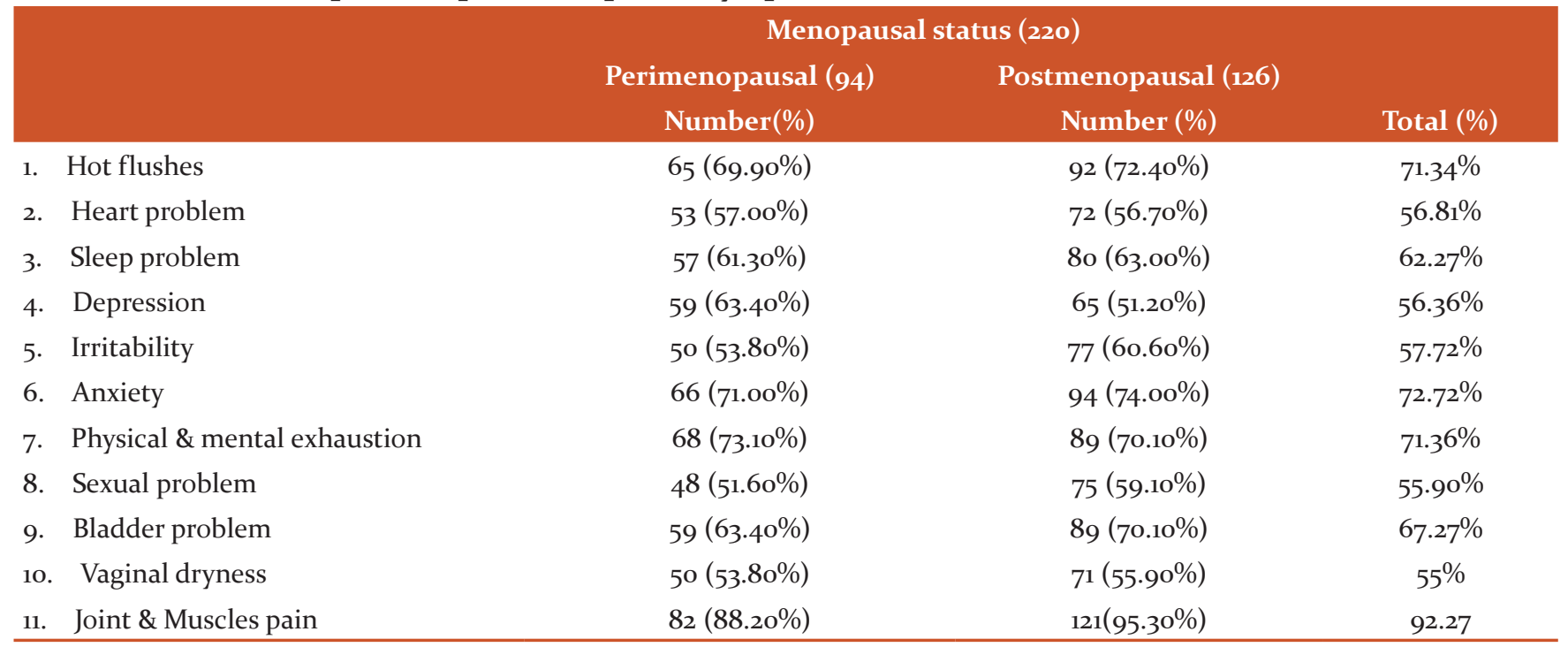

Table 2. describes the prevalence of menopausal symptom, major symptoms were joint and muscles pain (92.27) in total followed by anxiety $(72.72 \%)$, Hot flushes and night sweat (71.34\%), Physical mental exhaustion(71.36\%)) and Bladder problem (67.27\%)), sleep problem (62.2\%), Irritability
(57.7\%), heart problem (56.8\%), depression $(56.34 \%)$, sexual problem (55.9\%), and vaginal dryness (55\%). Difference between peri and postmenopausal symptoms are statically not significant.

Table 3: Peri and postmenopausal complain association using MRS subscale

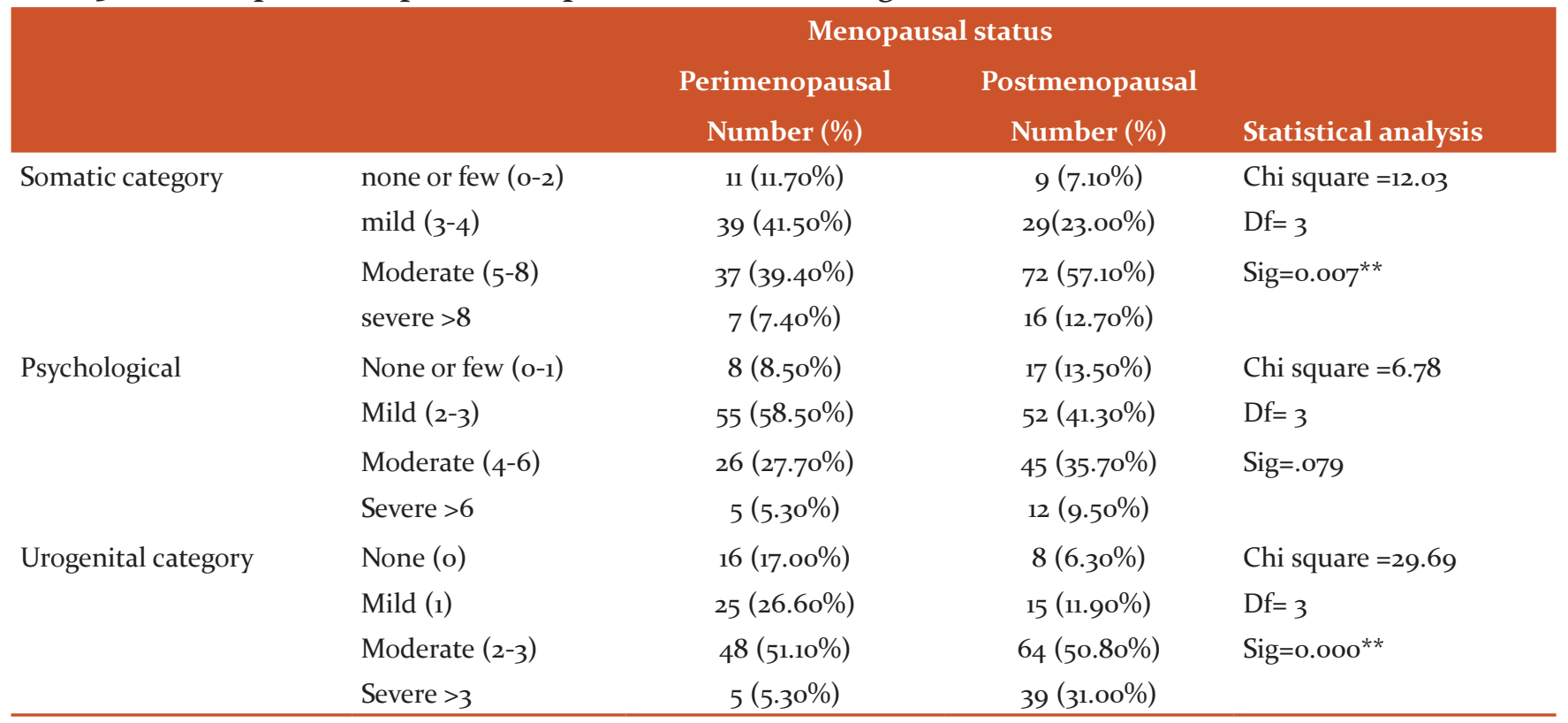

Table 3 In somatic symptoms of severity severe were higher proportion in postmenopausal women $(\mathrm{p}<0.05)$ statistically significant. In other hand psychological symptoms mild cases $(58.50 \%)$ higher in postmenopausal symptoms but statically not significant. The severity of Urogenital cases higher in postmenopausal women at proportions are highly $(\mathrm{p}>0.05)$.

\section{DISCUSSION}

Ageing is a specific unavoidable process besides its related to several changes that reduce the quality of life. Menopause is one of the natural processes of women's life. It's a specifical estrogen deficit state and affects many organs of the body those have sensitive for estrogen, thus declining level 
of estrogen raising cause of numerous physical, sexual and psychological changes of women's life. frequency of sign and symptoms differ over some time. Few complaints frequency prevalent in the perimenopausal phase and declines over a period, thus some complains raises gradually after the perimenopausal phase and more severe after postmenopausal life. ${ }^{12}$

In the present study menopausal mean age was $49.35 \pm 5.4$ years. This was earlier than the western part of the world, which is around $51.14 \pm 2.11$ years worldwide. ${ }^{2}$ Nevertheless, it is marginally higher than Indian population which is around 47.5 years. ${ }^{9}$ Which is in good same opinion and findings of others studies of Ganapathy et al. ${ }^{6}$ in Saudi Arabia (49.59 \pm 3.09 years), Khatoon $\mathrm{F}$ et al. ${ }^{13}$ in Lucknow $(50.33 \pm 5.26$ years), and Singh and Pradhan ${ }^{14}$ in Delhi (46.24 \pm 3.38 years). Among white women the median age ranges between 50 and 52 years and at perimenopause is 47.5 years in developed countries accompanied by slight evidence of increasing age at menopause over time. Beginning of these perimenopausal symptoms differ by race and nationality, influence by demographic and habits factors. ${ }^{15}$

There was no significant association found among respondents menopausal age, religion, caste, education status, occupation status, parity and SES. Our findings are similar to M. Deotale et al..$^{16}$ and S.K Panda et al. ${ }^{17}$, who found there was no association between the various sociodemographic factors and age onset of menopause.

Most common symptoms found in our study was joint and muscular pain in postmenopausal women $(95 \%)$ and perimenopausal $(88 \%)$. This finding was similar to many other studies where this complaint was found to be dominant. In a study by F. Khatoon et al..$^{13}$ and S.K Panda et al. ${ }^{17}$ found pain is the main symptoms and Rahman et al. ${ }^{18}$ also found same major symptoms. Hot flushes were most commonly reported by many Indian as well as in western countries studies, our study respondents reported mostly hot flushes $72.40 \%$ by postmenopausal and $70 \%$ by perimenopausal women. The proportion of hot flushes more in postmenopausal women as per the study of similar results Senthilvel et al. ${ }^{19}$ Nayak G et al. ${ }^{20}$ and hot flushes symptoms range between $0 \%$ to $80 \%$ worldwide. $^{21}$

Other somatic problem sleep disturbance in perimenopausal $61.3 \%$ and postmenopausal were $63 \%$ and heart discomfort almost the same $57 \%$ in peri and postmenopausal women in the study. These findings compare with the study done by Khatoon $\mathrm{F}$ et al. ${ }^{13}$ sleep disturbance $56 \%$, and heart disturbance $60 \%$ and also similar in the study of Panda Set al. ${ }^{17}$

This study shows most common psychological complains physical and mental exhaustion in perimenopausal in $73 \%$ and postmenopausal were $70 \%$, anxiety $71 \%$ in peri and $74 \%$ in postmenopausal women, depressive mood complains in peri and postmenopausal respectively $63 \%$ and $56 \%$. Irritability complains were found in study peri and postmenopausal were $53 \%$ and $60 \%$ these results also resembles with the study of Khatoon et al. ${ }^{13}$ also found depressive mood $70 \%$, Physical mental exhaustion $60 \%$ also similar study in Rahman et al. ${ }^{18}$

Urogenital complain in the study sexual problem in peri and postmenopausal women respectively $51 \%$ and $59 \%$, bladder problems were reported $63 \%$ in peri and $67 \%$ in postmenopausal women and Vaginal dryness $53 \%$ in peri and $55 \%$ in postmenopausal women in the study. Urogenital severity high in postmenopausal women it's statistical significance in the study similar result found in Pal A et al. ${ }^{22}$ also found in their study bladder problem (56\%) and vaginal dryness (53.3\%) much prevalent and similar result also in Ganapathy $\mathrm{T}$ et al., Panda $\mathrm{S}$ et al. ${ }^{6,17}$ Menopause is a natural phase of reproductive biorhythm of woman's life. Menopause is a biopsychological process and is a natural ageing system which signals a decreasing in body function. Due to the decreasing level of oestrogen, the body goes through various physiological alterations. This needs the combined medical and psychological support. Hence, the women can have the strength to overcome the severity of changes which affects the wellbeing of women. ${ }^{13}$

\section{LIMITATION}

Firstly, recall bias was unavoidable because retrospective information was collected for menopausal symptoms in the preceding one month which was difficult for the elderly women to remember. Secondly the MRS questionnaire is in English language and the women in the slum were not well versed with the language thus it was explained by the principal investigator in Odia language in an interview and filled accordingly. Before starting the study, pilot testing was done for 30 participants.

\section{CONCLUSION}

Most common symptoms perceived in the study were joint and muscular pain, followed by anxiety, hot flushes and physical mental exhaustion. The severity of morbidities was higher among postmenopausal women in somatic and urogenital subscales. The awareness regarding menopausal symptoms and its management should be enhanced by the staff of urban health and training centre.

\section{ACKNOWLEDGEMENT}

We are thankful to all Urban Health Training Centre staff to help us conduct survey and data collection, also thankful our 
professors of the department to analysis and guide for article writing.

The authors gratefully acknowledge all volunteers for participation in this study. We acknowledge the immense help received from the scholars whose articles are cited and included in references to this manuscript. The authors are also grateful to authors/editors/publishers of all those articles, journals and books from where the literature for this article has been reviewed and discussed.

\section{Source of Funding: None}

\section{Conflict of Interest: None.}

\section{REFERENCES}

1. Sherman S. Defining the menopausal transition. Am J Med. 2005;118(12 SUPPL. 2):3-7.

2. Organization WHO. Research on menopause. Geneva, Switzerland; WHO Technical Report Series; 1996: No. 866.

3. Hachul H, Polesel DN, Nozoe KT, Sanchez ZM, Prado MCO, Andersen ML, et al. The Age of Menopause and their Associated Factors : A Cross-Sectional Population-Based Study. J Women's Health Care. 2016;5(5):1000335.

4. Meeta, Digumarti L, Agarwal N, Vaze N, Shah R, Malik S. Clinical practise guidelines on menopause: *An executive summary and recommendations. J Mid-life Health 2013;4:77-106.

5. Nayak G, Kamath A, Kumar P, Rao A. A study of quality of life among perimenopausal women in selected coastal areas of Karnataka, India. J Mid-life Health 2012;3:71-5.

6. Ganapathy T, Al Furaikh SS. Health-related quality of life among menopausal women. Arch Med Health Sci 2018;6:16-23.

7. Mahajan N, Aggarwal M, Bagga A. Health issues of menopausal women in North India. J Mid-life Health 2012;3:84-7.

8. Avin Alva BR, Chethan TK. A Study to Assess the Average Age of Menopause and Menopause Associated Symptoms among Rural Women in Mangalore, Karnataka. Ntl J Community Med 2016; 7(5):404-408. Available from: www.njcmindia.org

9. Unni J. Third consensus meeting of Indian Menopause Society (2008): A summary. J Midlife Health. 2010;1(1):43.

10. Santhi Vadugu, Vani Lanke. "The Menopause Rating Scale (MRS) in Indian Women". Journal of Evidence-based Medicine and Healthcare; Volume 2, Issue 54, December 07, 2015; Page: 8789-8791, DOI: $10.18410 / \mathrm{jebmh} / 2015 / 1228$.

11. Mohd Saleem S. Modified Kuppuswamy socioeconomic scale updated for the year 2019. Indian J Forensic Community Med. 2019;6(1):1-3.

12. Ahsan M, Mallick A, Singh R, Prasad R. Assessment of menopausal symptoms during perimenopause and postmenopause in tertiary care hospital. J Basic Clin Reprod Sci. 2015;4(1):14.

13. Khatoon F, Sinha P, Shahid S, Gupta U. Assessment of menopausal symptoms using a modified menopause rating scale (MRS) in women of Northern India. Int J Reprod Contracept Obstet Gynecol 2018;7:947-51. International. Int J Reprod Contraception, Obstet Gynecol. 2018;7(3):947.

14. Singh A, Pradhan SK. Menopausal symptoms of postmenopausal women in a rural community of Delhi, India : A cross-sectional study. 2014;5(2):2-7.

15. Gold EB. The Timing of the Age at Which Natural Menopause Occurs. Obstet Gynecol Clin North Am. 2011;38(3):425-40.

16. Deotale M, Ranganathan U, Mankeshwar R, Akarte S. Study of epidemiological features of health problems in perimenopausal and postmenopausal women in an urban community. Int J Med Public Heal. 2015;5(2):147.

17. Panda SK. Assessment of Health Status in Peri- and Postmenopausal Women Residing in Urban Slums. J Med Sci Clin Res. 2018;6(5):490-6.

18. Rahman S, Zainudin S, Mun V. Assessment of menopausal symptoms using modified Menopause Rating Scale (MRS) among middle-age women in Kuching, Sarawak, Malaysia. Asia Pac Fam Med. 2010;9(1):5.

19. Sumathi Senthilvel SV, P. S. Anju, Anjana Sukumaran JS. Assessment of symptoms and quality of life among postmenopausal women in a tertiary care hospital in Kochi, South India: A hospital-based descriptive study. J Midlife Health. 2018;9:18590.

20. Gayathry Nayak AK, Pratap Kumar AR. A study of quality of life among perimenopausal women in selected coastal areas of Karnataka, India. J Midlife Health. 2012;3(2):71.

21. Mahawar P, Sakalle S, Dixit S, Rathore D, Gangwani D. Assessment of Morbidity Pattern and Its Knowledge Assessment of Peri- and Postmenopausal Women Using Menopause Rating Scale - A Cross-sectional Study. Ann Community Heal. 2017;5(2):2-6.

22. Pal A, Hande D, Khatri S. Assessment of menopausal symptoms in perimenopause and post-menopause women above 40 years in rural area Maharashtra (India). Int J Healthcare Biomed Res. 2013;1(3):166-174. 